\title{
APSA Strategic Plan in Brief
}

\section{INTRODUCTION BY STEVEN RATHGEB SMITH}

Since 2014, APSA has been engaged in an extensive strategic planning process. After feedback and consultation from the APSA Council and the membership, the strategic plan was finalized this year. In the document, APSA details its commitment to the promotion of the scholarly understanding of political ideas, norms, behaviors, and institutions to inform public choices about government, governance, and public policy.

As reflected in the plan, APSA also supports excellence in scholarship and teaching and informed, inclusive discourse about politics, policy and civic participation. The association is comprised of a diverse community of scholars, teachers, students, and practitioners who bring wide-ranging interests, methodologies, and perspectives to the analysis and conduct of government and politics. The association disseminates information, facilitates collaboration among its members, and publicizes research findings on important theoretical and political issues, and publishes a variety of materials relevant to the discipline. The association is dedicated to enhancing the capacity of political scientists to conduct research, offer effective teaching, develop professionally, and broadly communicate their ideas within the discipline and to wider publics.

APSA is committed to transparency, open enquiry, civil discourse, scholarly pluralism, high standards of ethics and integrity, and a global perspective. The association welcomes continuing feedback on the plan from members. Please email the executive director, Steven Rathgeb Smith, with any comments at smithsr@apsanet.org.

\section{VISION}

The American Political Science Association (APSA) promotes scholarly understanding of political ideas, norms, behaviors, and institutions to inform public choices about government, governance, and public policy.

\section{MISSION}

The American Political Science Association (APSA) supports excellence in scholarship and teaching as well as informed discourse about politics, policy, and civic participation. The Association promotes a lively, diverse community of scholars, teachers, students, and practitioners who bring wide-ranging interests, methodologies, and perspectives to the analysis and conduct of government and politics. The Association disseminates information, facilitates collaboration among its members, publicizes research findings on important theoretical and political issues, and publishes a variety of materials relevant to the discipline. APSA enhances the capacity of political scientists to conduct research, improve teaching, develop professionally, and communicate their ideas within the discipline and to wider publics.

\section{VALUES}

APSA is committed to transparency, open enquiry, scholarly pluralism, high standards of ethics and integrity, and a global perspective.

\section{THEORY OF CHANGE}

If scholarly understanding of political ideas, norms, behaviors, and institutions is to flourish and to inform public choices, these conditions must be fulfilled:
1. A vibrant and healthy system of knowledge generation and dissemination. This requires, in turn:

a. An open political science profession: people are able to get into the knowledge system, which they will do principally through a $\mathrm{PhD}$ and getting a job related to knowledge generation, usually in a university but also in other areas, such as think tanks or government.

b. A profession that welcomes and promotes diversity in terms of its members' backgrounds, identities, views, fields of study, and methodological approach, because this diversity will ensure that the discipline generates the most productive ideas.

2. The development and maintenance of mechanisms through which scholarly knowledge can be shared, reviewed, challenged, and debated:

a. Outlets for the knowledge and ideas that political scientists generate.

b. A system for ensuring that they generate this knowledge and the ideas in ways that meet the standards of science.

c. The means of ensuring the free exchange of ideas and collaboration, including between groups of political scientists with similar interests and expertise.

3. There are a sufficient number of individuals with the skills, ability, connections, and resources to participate effectively in the knowledge generation and dissemination system.

4. The acceptance of political science as a legitimate component of the broader political-economic system. In particular, public acceptance hinges on: public understanding and appreciation of political sciencethe benefits, what it can and cannot do, and the risks of research; legal/formal support for the conduct of academic research including protections for academic freedom data collection, and accessible archives; and public and social financial support for political science.

5. Efficient and diverse mechanisms for engaging the public in thinking about and debating political science and with policy and law-makers to inform public choices about government, governance, and public policy.

\section{OVERARCHING GOALS}

APSA's primary, overarching meta-goal will be to increase the value proposition of APSA membership, thereby increasing the number of APSA members. In support of increasing the value proposition of APSA membership, we will pursue the following long-term goals:

1. To provide and/or enable the knowledge production system-that is, the mechanisms through which knowledge can be shared, reviewed, challenged, and debated for our members and the broader political science community.

2. To provide support for political scientists entering the profession, and to help political scientists in the profession flourish by supporting them in their research, teaching, and professional service.

3. To promote and encourage diversity and inclusion in the profession.

4. To foster public engagement with the discipline and promote connections between political scientists and society at the local, state, national, and international level. 
5. To advocate on behalf of the discipline and political scientists.

6. To maintain APSA's organizational efficiency and financial stability.

\section{CRITICAL OBJECTIVES FOR 2017-2019}

In order to achieve these long-term goals, over the coming three years we will focus on the following priorities.

1. Successfully launch the new open access journal and ensure high quality editorial teams are secured for APSA's 4 other journals.

2. Grow the annual meeting to at least 7,000 attendees.

3. Grow total individual membership by $3 \%$ in FY2017, and a further 1\% in FY 2018 and 1\% in FY 2019. Grow departmental membership by $5 \%$ per year.

4. Grow international, diversity and inclusion, and Centennial Center program participants by an average of $33 \%$

5. Deepen and enhance our approach to support for teaching and learning.

6. To complement existing programs that focus on specific objectives, we will develop cross-organizational strategies for professional development, public engagement, internationalization and diversity and inclusion.

7. Meet the Ralph Bunche Endowment Fund campaign goal of $\$ 1.25$ million.

8. Improve the physical assets for a safe working environment and income potential.

9. Continuous IT upgrades to website, database, and annual meeting submission system.

10. Complete the governance reform process.

\section{PROGRAMMATIC OBJECTIVES FOR 2017-2019}

The plan now describes all of the objectives that will help APSA achieve its mission, grouped under each of the long-term goals and by APSA department.

Goal 1: To provide and/or enable the knowledge production system-that is, the mechanisms through which knowledge can be shared, reviewed, challenged, and debated for our members and the broader political science community.

- Successfully launch the new open access journal and ensure high quality editorial teams secured for APSA's 4 other journals.

- Grow the annual meeting to at least 7,00o attendees.

- Grow exhibitors in the exhibit hall by $10 \%$.

Goal 2: To provide support for political scientists entering the profession, and to help political scientists in the profession flourish by supporting them in their research, teaching, and professional service.

- To complement existing programs that focus on specific objectives, we will develop cross-organizational strategies for professional development, public engagement, internationalization and diversity and inclusion.

- Deepen and enhance our approach to support for teaching and learning.

- Grow international, diversity and inclusion, and Centennial Center program participants by an average of $33 \%$.
- Expand international programming, specifically with political science communities in non-OECD countries.

- Increase the number of RBSI, Minority Fellowship, and Mentoring Program participants.

- Expand outreach and recruiting activities for the Congressional Fellowship Program to achieve a more diverse class of fellows both across the three fellowship categories directly sponsored by APSA (political science, journalism, telecommunications) and among outside-sponsored fellows.

- Expand professional development programming.

- Increase the percentage of APSA members who join/renew sections by $3 \%$.

- Improve the quality of data collected and quantity of reports available for APSA members and the public.

- Maintain current high quality and delivery of APSA awards.

Goal 3: To promote and encourage diversity and inclusion in the profession.

- APSA staff will prepare for review by the council a summary report on the overall diversity goals of the association including committee and council appointments.

- Encourage APSA Sections to incorporate diversity and inclusion consideration in their committee and governing council appointments. By 2019, incorporate section information and input into the annual diversity report.

- Increase the number of RBSI applicants to 80 and participants to 70 by 2019, and increase the number of RBSI alumni who apply to doctoral programs from $67 \%$ to $75 \%$ by 2019 and complete their $\mathrm{PhD}$.

- Increase the number of Minority Student Recruitment Program (MSRP) students in the database from 442 to 550 over three years. Increase the number of participating MSRP $\mathrm{PhD}$ departments from 40 in 2015-2016, to 50 in 2017 and 60 in 2018.

- Increase the number of applications to the Minority Fellowship Program from individuals from under-represented backgrounds by $25 \%$ by 2019; the number of MFP Fellows from 12 funded to 20 (15 funded and 5 unfunded) by 2019 , and $\mathrm{PhD}$ attainment and academic job placement for each successive MFP cohort.

- Increase the number of APSA Mentors by over $60 \%$, over the next three years, and increase the number of mentor matches made in keeping with increase in new mentee requests.

Goal 4: To foster public engagement with the discipline and promote connections between political scientists and society at the local, state, national, and international level.

- Continue to develop APSA's public engagement initiatives into a robust stand-alone program.

- Support political scientists with resources, training, and opportunities to share their research: workshops and panel discussions on communicating political science; opportunities to liaise with media through the experts database; and opportunities to liaise with the public through public talks and events.

- Connect the public-including policymakers and the media-to information from the discipline through: public talks, online video library, other online resources, the experts database, Capitol Hill briefings, and exhibitions.

- Use PSNow as the APSA hub for virtual engagement with the public: repurpose articles from other APSA products to share with the public, with liberal use of photos and video, profiles of members, and a forum to hold effective discussion and engagement with the public. 
- Develop new programming to highlight insights and expertise gleaned by alumni of the Congressional Fellowship Program.

Goal 5: To advocate on behalf of the discipline and political scientists.

- To further build APSA's in-house advocacy capacity while developing core constituents to engage more actively on their own in advocacy on funding issues.

- Continue to advocate on behalf of the profession and academic freedom.

Goal 6: To maintain APSA's organizational efficiency and financial stability.

- Complete the governance reform process.

- Continuous IT upgrades to website, database, and annual meeting submission system.

- Meet the Ralph Bunche Endowment Fund campaign goal of $\$ 1.25$ million.

- Improve the physical assets for a safe working environment and income potential.

- Provide proper stewardship of APSA's financial resources.

- To maintain $\$ 35$,00o in donations of unrestricted and restricted gifts to APSA annually.

- Greater and better awareness of APSA and its work among key audiences.

- All major APSA programs are measuring and learning from their results.

\section{RESOURCE IMPLICATIONS}

Implementing this strategic plan has implications for new revenues and expenditures. Typically a capital or fundraising campaign will incur costs at $20 \%$ of the campaign total, and the campaign can generate coverage for some of those costs throughout the three year period. We project adding one full-time employee strategic hire to implement the growth goals for professional development, programming, and annual growth. Upgrading the annual meeting submission system and web-based functionalities will also incur costs. Meeting the membership and annual meeting growth objectives will create new revenues. We will use this plan to guide our budgeting process on an annual basis, with mid-year assessments at the director and senior staff level. For reference, treasurer's reports from the past 5 years are located on APSAnet.org.
RESPONDING TO NEW DEVELOPMENTS: THE STRATEGIC SCREEN

This plan uses the overarching, long-term goals as a framework for describing the objectives and strategies APSA will pursue over the next three years. However, new opportunities and challenges may arise. As such, APSA will review new opportunities, threats, and development against the goals and against APSA's Strategic Screen decision-making criteria as follows:

- The extent to which the program/activity/initiative contributes to the goal of increasing membership.

- The extent to which the program/activity/initiative contributes to the mission of APSA, including scholarship.

- How its purpose is still relevant to the needs of members and the field.

- How the program/activity/initiative compares favorably with competitive programs/activities.

- Whether the program is the most cost-effective way of achieving the desired outcomes.

- To what extent APSA has the institutional knowledge and staff capacity to deliver the program.

\section{MONITORING AND EVALUATION}

APSA will evaluate progress toward meeting these goals on an annual basis, drawing on progress reports from each department and assessment against the association's strategic screen for decision-making. Annual review of the plan also will include an assessment of any changes to threats and opportunities to the association.

More broadly, success in achieving APSA's mission over time will best be measured by:

- The "flow" of entrants into the profession at the doctoral level and above.

- The diversity and inclusion of its members' backgrounds, identities, views, fields of study, and methodological approach.

- The openness and efficiency of the channels and fora in which this thinking can be reviewed, challenged, and debated.

- The quality of scholarly understanding generated-for example, the extent to which it meets the standards of scholarship.

- Levels of public acceptance and understanding of the potential contribution of political science.

- Evidence of public choices being informed by scholarly understanding of political ideas, norms, behaviors, and institutions. 